\title{
EXPERIMENTAL RESEARCH IN BRAZED PLATE-TYPE HEAT EXCHANGERS
}

\author{
Rostislav Li ${ }^{1}$, Aleksandr Odintsov ${ }^{1}$, Sandra Sidenko ${ }^{1,2}$ \\ ${ }^{1}$ SIA “EKO AIR", Latvia; ${ }^{2}$ Riga Technical University, Latvia \\ ekoair@icloud.com, aleksandr.odintsov@ekoair.lv, sandysid@inbox.lv
}

\begin{abstract}
Experimental studies of a heat exchanger with an improved plate's heat transfer surface are carried out. In the article, various types of solders were investigated and on the basis of the obtained results the technological process of soldering was developed. Testing for the leakage and destruction limit of the heat exchanger was done. The results showed that in comparison with the traditional copper solder in aggressive environments the developed solder composition is close to the chemical composition of stainless steel grades 304/316 and has the same stainless properties as the base material, which provides higher resistance. Tests for the leakage and final strength showed that the additional reinforcing elements added in the design of the heat exchanger improve the reliability of the solder joint, as well as the overall strength of the structure in comparison with the analogue.
\end{abstract}

Keywords: plate heat exchangers, strength, pressure, heat transferring surface, brazed joints.

\section{Introduction}

Plate-type heat exchangers consist of a package of thin heat transferring plates with corrugated surfaces brazed together in a vacuum environment. Plates are made of sheet material using cold stamping, as a result of which a corrugated surface is formed with an interleaving of ledges and dints. The shape and size of the corrugations are different and depend on the type of the heat transferring plate. Holes on the edges of the plate are used for passing of the working media in the channels formed by the adjacent plates. The heat exchanger plates are assembled into packages depending on the demanded quantity and are additionally reinforced by the outer reinforcement plates to create a technological system for filling the parallel channels.

Such brazed plate heat-exchangers (BPHE) found wide application in many areas of modern industry and in comparison with shell-tube have advantages as compactness, a high heat-transfer coefficient with a relatively small hydraulic resistance.

In this work the variant of BPHE with improved plate's heat transferring surface was optimized and produced. However, for launching into the mass-production the newly developed version of the BPHE it was necessary to make a series of studies to improve the strength characteristics.

To achieve the goal it was obligatory to approach some tasks: investigate different types of brazing alloy on the prototype preproduction models and also to make tests of integrity and failure.

\section{Materials and methods}

The experimental studies were carried out on the BPHE type NB538 (maximal operating pressure NB - 31bar, type of plate - H) with corrugations type "fish bone" and improved heat transferring surface of the plates. Plates are made from sheet material (stainless steel grades), with a thickness of $0.3 \mathrm{~mm}$ using cold stamping. Such type of BPHE is used in the heating systems of buildings and rooms. The design of the BPHE (a) and a sample of the improved plates shape (b) are shown in Fig. 1.

a)

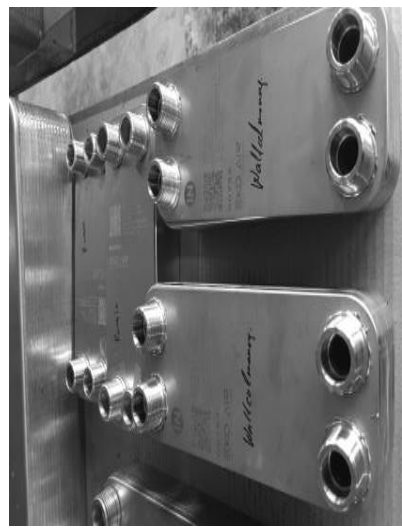

b)

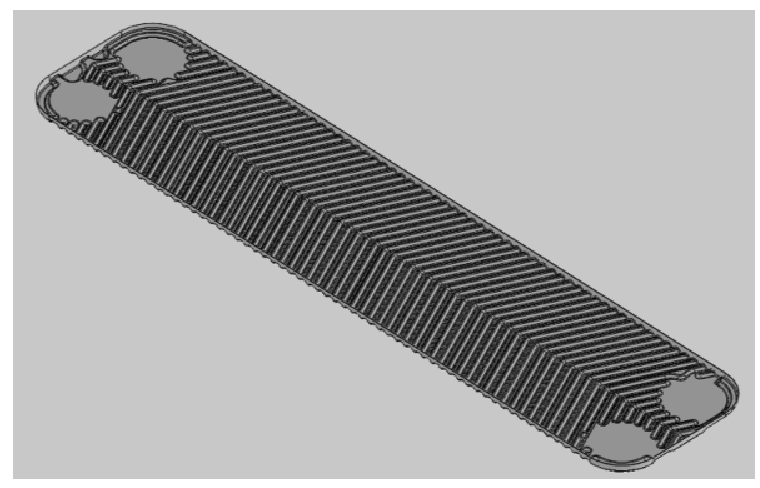

Fig. 1. Design of heat exchanger (a), plate heat exchangers with corrugated "fish bone" type (b) 
To improve the quality of the brazing alloy joints of the heat exchanger plates among themselves [1] brazing alloy with different types and base components was studied: powdered, amorphous singlelayer, amorphous combined. Solders were considered as the basic composition: $\mathrm{Fe}-20 \mathrm{Ni}-20 \mathrm{Cr}-10 \mathrm{Cu}-$ 7P-4Si, B-Fe39CrNiCuPSi, AMS4777, MBF51 and powdered cathode copper with a purity of $99.9 \%$, with the addition of binding components.

Towards the final goal, for the brazing alloy joints of the heat exchanger plates, various temperature regimes of brazing alloy were considered to ensure the optimum state of the solder melt and the dwell time of the manufactured experimental samples of heat exchangers.

The experiments were carried out on specialized equipment, the furnace with vacuum level up to $10^{-7}$. Temperature, time and vacuum level in the furnace were taken with the help of a specialized controller Demig, which is performing the functions of controlling and recording of the current parameters.

Figure 2 shows a general view of the furnace with a controller and a typical record of the parameter recorder.
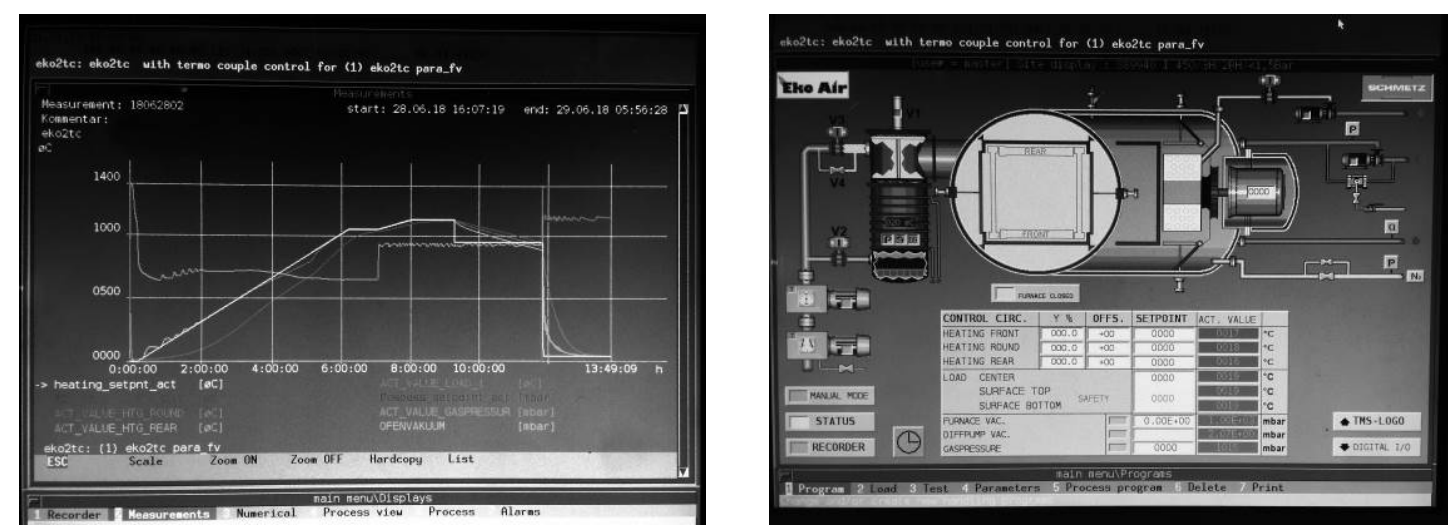

Fig.2 Recorder diagram and controller panel of furnace

Studies of the microstructure [2;3] of the obtained brazing alloy joints were carried out on samples cut out in characteristic brazed joints, with the subsequent manufacture of test sections. The samples were cut on Struers Discotom-10 machines with a 66A25 cutting disc and a Precision Cut Accutom-5 with a 50A13 cutting disc, with a cutting speed of $0.1 \mathrm{~mm} \cdot \mathrm{s}^{-1}$. Next, the cut samples were poured into Levofast plastic and PhenoCure ${ }^{\mathrm{TM}}$ plastic, and then carefully grinded and polished to a roughness of $1 \mu \mathrm{m}$. Fig. 3a shows an example of the sample under study. Features of the microstructure of the obtained samples were investigated using a Zeiss Axio Imager A2m optical microscope shown in Fig. 3b.

a)

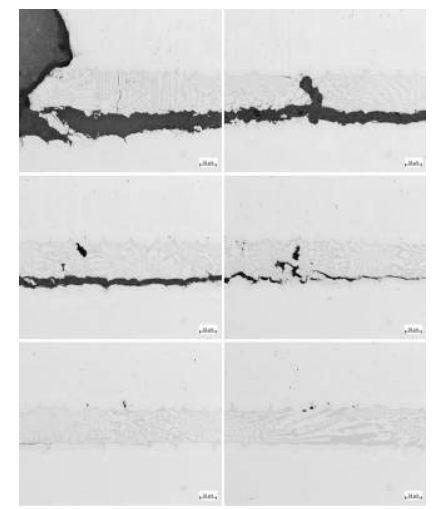

b)

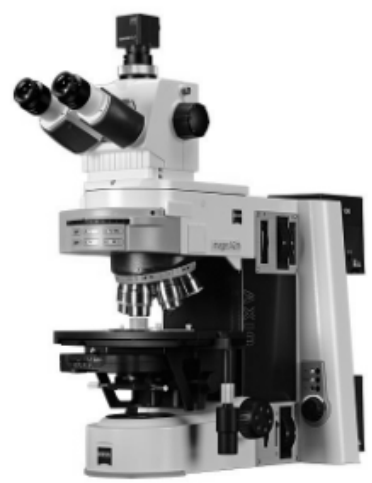

Fig.3. Sample study (a) Zeiss Axio Imager A2m optical microscope (b)

The samples for energy dispersive X-ray spectroscopy are shown in Fig. 4.

Tests for leakage of a manufactured sample of a plate heat exchanger with improved strength characteristics were carried out on testing equipment Nolek with control of the pressure. 
Tests on the destruction of the heat exchanger were carried out using a specialized testing equipment Tyroller Hydraulik Herzberg GmbH designed for testing heat exchangers or equipment worked under pressure [4].
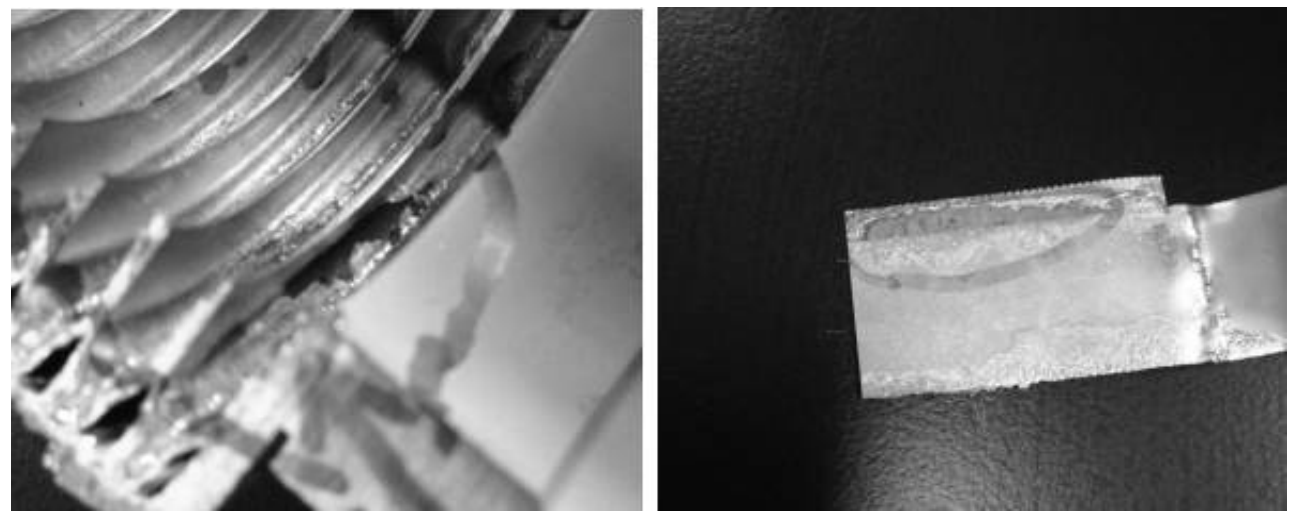

Fig.4. Sample for energy dispersive X-ray spectroscopy

\section{Results and discussion}

The results of the study of brazing alloy showed that during the brazing cycle the presence of oxygen in the binder and solvent has the most significant effect on the quality of the brazed joints. The presence of oxygen when performing heating dissociates and reacts with the components of the brazing alloy, forming compounds that prevent the formation of high-quality brazing alloy joints.

To avoid these defects before performing the homogenization stage of heating the set of the experimental heat exchangers and the dwell stage the following technologies were added into the brazing cycle: additional cleaning of the furnace working volume, creating high vacuum in the working volume of the furnace and additional blowing of the working volume with nitrogen.

The temperature and time chart of the brazing cycle are shown in Table 1. The dwell time at the homogenization and brazing stages was calculated based on the mass of the experimental samples in the furnace with heat exchangers placed into the working space and the size of the assembled plate packs.

Table 1

Temperature and time chart of the brazing cycle

\begin{tabular}{|l|l|c|c|}
\hline No. & Stage & Temperature, ${ }^{\mathbf{C}} \mathbf{C}$ & Time, hours \\
\hline 1. & Ramp & 150 & 0.5 \\
\hline 2. & Dwell & 150 & 1.0 \\
\hline 3. & Ramp & 450 & 1.0 \\
\hline 4. & Dwell & 450 & 2.0 \\
\hline 5. & Ramp & $600-650$ & 1.0 \\
\hline 6. & Dwell & $600-650$ & 2.0 \\
\hline 7. & Start diffusion pump and pump to high vacuum for 30 min & - & - \\
\hline 8. & Shut off diffusion pump and introduce pp N2 at 10-2 mbar & - & - \\
\hline 9. & Ramp & $930-950$ & 6.0 \\
\hline 10. & Dwell & $930-950$ & 1.0 \\
\hline 11. & Ramp & 1100 & 0.3 \\
\hline 12. & Dwell & 1100 & 1.0 \\
\hline 13. & Cool & $900-800$ & - \\
\hline 14. & High speed cooling & To the room & - \\
\hline
\end{tabular}

Analysis of the joints of the prototypes of the working plates in places of capillary brazed joints and connections with reinforcing elements of the design of the prototype of the heat exchanger was carried out using micro- and spectral analysis methods to study the distribution of elements in different 
areas of the compound with different thicknesses of materials, as well as to work out the best way to perform the brazing process to avoid oxidation of brazing alloy elements.

The concentration and content of brazing alloy chemical elements are shown in Figure 5.

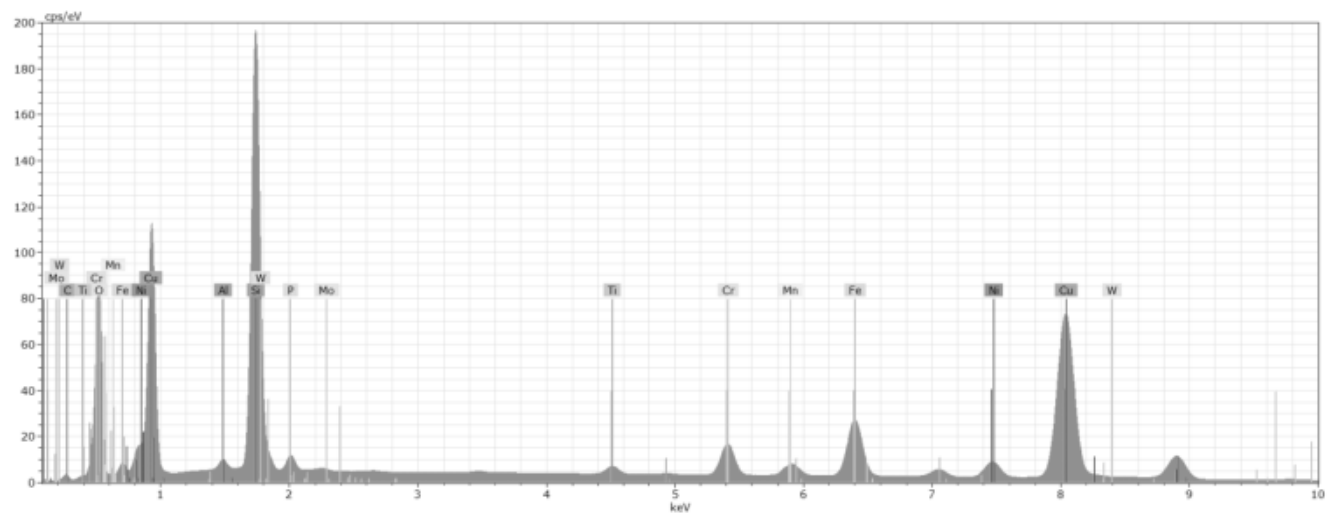

Fig. 5. Result of spectral analysis of solder

The resulting studies show that connection of the prototypes of working plates in places of capillary brazed joints and connections with reinforcing elements of the design of the prototype heat exchanger, as well as transition zones between the main material and brazing alloy material, are similar in composition to the chemical composition of stainless steel 304/316 grades and have the same anti-corrosion properties, as well as the base material of the prototypes of working plates, providing a higher resistance compared to traditional solder (copper) in conditions of aggressive modern media.

Based on the results of the study the prototype of the heat exchanger with improved brazing alloy characteristics and configuration of the heat exchanger plates was manufactured. Tests were carried out for the leakage and structural strength.

During the testing cycle, hydraulic fluid is pumped into the heat exchanger under pressure. In this case, the tests take place in several stages: "filling"; "pumping-holding"; "forcing"; "reset".

At the "filling" stage, the heat exchanger under test is filled with hydraulic fluid. At the "pumping-holding" stage, additional volume of hydraulic fluid is pumped to ensure filling of all the cavities of the heat exchanger. At the "forcing" stage, an overpressure is created. At the "reset" stage, the overpressure is relieved to safely disconnect the tested equipment from the hydraulic system of the test equipment.

The automatic monitoring and recording system records the instantaneous overpressure parameters using pressure sensors with a plot of pressure versus time. Registration is carried out until the equipment under test is destroyed or the maximum working pressure is reached. Failure is detected by hydraulic fluid leak sensors, or by a critical pressure drop. The graph of dependence of the pressure from time for the base (line 1) and improved (line 2) variants of the heat exchanger prototypes are shown in Fig.6.

Comparative analysis of the test results from Fig. 6 showed the presence of three characteristic zones.

The first zone is characterized by the fact of deformation and changing of the internal volume of the heat exchanger under the created overpressure. For both variants of the heat exchangers (the base and improved) the limiting overpressure is equal to $P_{\text {ovr }} \approx 25 \mathrm{Bar}$. Only for the base case, the $\mathrm{P}_{\text {ovr }}$ limit value is reached in 60 seconds later than for the optimized one.

The second zone is characterized by the fact that at this moment the pressure is increasing, injected by the pump unit, without changing of the internal volume. At this stage you can observe deformation of the construction of the heat exchanger - the outer reinforcing plates, until the moment leakage appears and the maximal strength of the heat exchanger is reached. The main areas of destruction are the zones of brazed joints, which are subjected to tensile stresses in the base metal as a result of deformation exceeding the allowable values for austenitic steels. In this case, for the base 
model, the limiting overpressure reaches $P_{\text {ovr }} \approx 56 \mathrm{Bar}$ at 280 seconds and for the improved version $P_{\text {ovr }} \approx 85$ Bar at 315 seconds.

The third zone is characterized by the fact that for both variants of heat exchangers the pressure drop is noticeable, which is associated with the loss of tightness of the channel and the growth of the destructed zone. When fixing a significant pressure drop or leakage of hydraulic fluid, the pumping equipment is turned off.

The graph shows that in comparison with the base model the improved version of the heat exchanger withstands the maximum pressure $34 \%$ better.

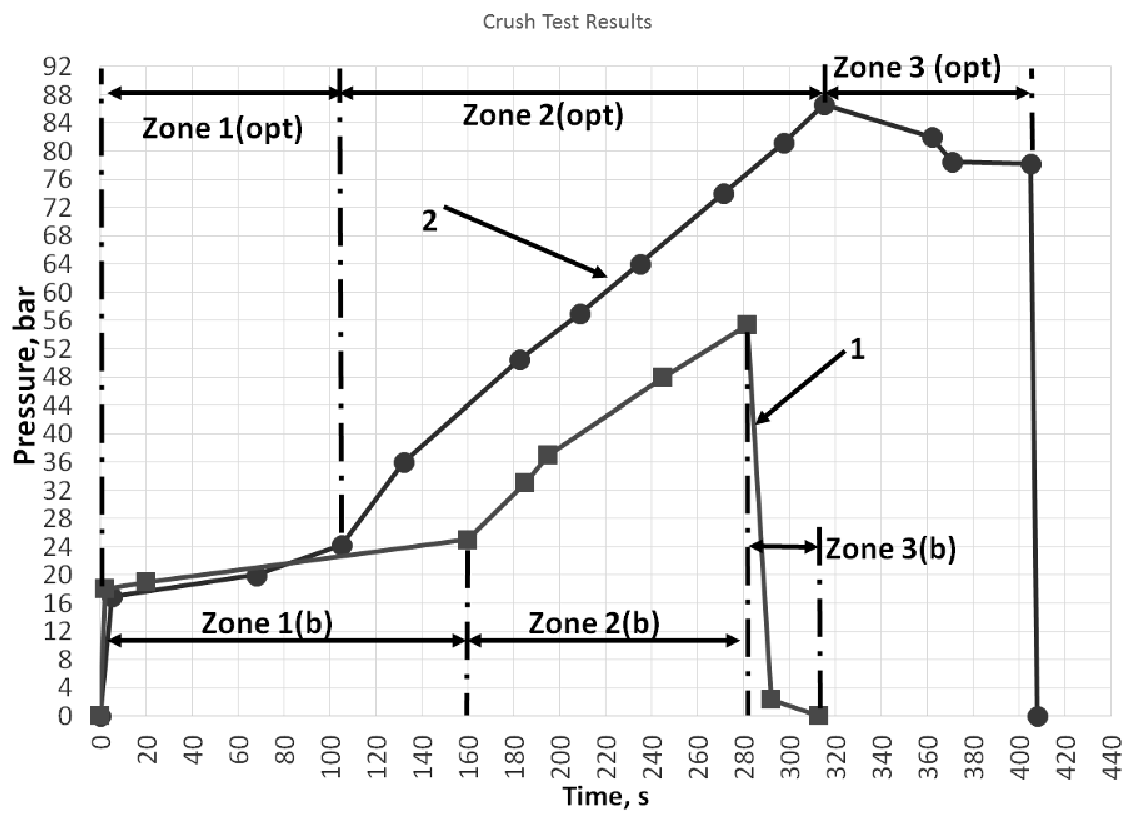

Fig. 6. Graph of pressure versus time for basic (1) and improved (2) heat exchanger variants

\section{Conclusions}

1. Performed micro- and spectrographic analyses made it possible to study the distribution of elements in different zones of joints of the heat transferring plates. The optimal variant of the soldering process was chosen to avoid oxidation of solder elements. The obtained solder joints, as well as transition zones are similar in composition to the chemical composition of stainless steel grades 304/316 and have the same anti-corrosion properties as the base material, providing a higher durability compared to traditional solder in aggressive environments.

2. During testing for the tightness and strength of the heat exchanger's constructions three characteristic zones were present. In the first zone, when deformation and changing of the internal volume of the heat exchangers occur, the limit of excess pressure for both cases reaches $P_{o v r} \approx 25$ Bar. The second zone, where deformation of the structure of the heat exchangers occurs covering reinforcement plates until the moment leakage appears and reaching of the maximal strength of the heat exchanger, revealed that the limit of excess pressure for the base model was $P_{\text {ovr }} \approx 56$ Bar and for the improved model $P_{\text {ovr }} \approx 85$ Bar.

3. On the basis of the conducted tests it can be assumed that the manufactured improved version of the prototype of the heat exchanger in comparison with the base model showed increasing in the final strength of the structure $\approx 34 \%$. That will respectively provide a longer service life.

\section{Acknowledgements}

SIA "EKO AIR" study No. 2.2. "Increasing the strength of heat exchangers soldering joints" within the project "Establishment of the Centre of Mechanical Engineering Competence", for which LLC "MAŠIINBŪVES KOMPETENCES CENTRS" and the Central Finance and Contracting Agency signed the contract No. 1.2.1.1/16/A/ on October 11, 2016 003, Project No 1.2.1.1/16/A/003. 


\section{References}

[1] Kalinichenko N.P., Viktorova M.O. Atlas of defects of solder joints ed. Tomsk Polytechnic Institute - Tomsk, TPU, 2012, 83 p. (In Russian)

[2] Oreshenkova E.G. Spectral analysis, M.: Higher. school, 1982, 375 p. (In Russian)

[3] Rauscher C. Fundamentals of spectral analysis. Transl. from English SM Smolsky / Ed. Yu. A. Grebenko - M, 2005. (In Russian)

[4] Zhezhera N.I. Automation of testing of products for tightness. Orienburg: GOU OGU, 2005 475 p. (In Russian) 